\title{
Transradial Versus Transfemoral Approach for Coronary Angiography in Females with Prior Bypass Surgery
}

Ahmed Amro ${ }^{1}$, Kanaan Mansoor ${ }^{2}$, Mohammad Amro ${ }^{3}$, Hisham Hirzallah ${ }^{1}$, Amal Sobeih ${ }^{4}$, Damir Kusmic ${ }^{5}$, Ziad Abuhelwa ${ }^{6}$, Majd Kanbour ${ }^{1}$, Adee Elhamdani ${ }^{7}$, Obadah Aqtash ${ }^{5}$, Mehiar Elhamdani ${ }^{1}$

1. Cardiology, Marshall University, Huntington, USA 2. Internal Medicine, Marshall University Joan C. Edwards School of Medicine, Huntington, USA 3. Internal Medicine, Misr University for Science and Technology, Cairo, EGY 4. Internal Medicine, Al-Najah University, Nablus, PSE 5. Internal Medicine, Marshall University, Huntington, USA 6. Internal Medicine, An-Najah National University, Nablus, PSE 7. Internal Medicine, Allegheny Health Network, Pittsburgh, USA

Corresponding author: Ahmed Amro, amro@marshall.edu

\section{Abstract}

\section{Background}

Multiple studies have shown that trans-radial access (TRA) for women undergoing coronary angiography/intervention (CA/I) has a lower risk of vascular access site complications as compared with trans-femoral access (TFA). In patients who had previously undergone coronary artery bypass grafting $(\mathrm{CABG})$, studies also showed no significant difference between TRA and TFA in terms of contrast amount (CA), procedure time (PT), and fluoroscopy time (FT). However, those studies mainly included men. Limited information is available on the relative merits of TRA as compared with TFA for cardiac catheterization in females who previously undergone CABG. The purpose of this study was to determine the efficacy and safety of TRA versus TFA in women with prior CABG surgery who are undergoing CA/I in regard to CA, PT, and FT.

\section{Methods}

In this single-center retrospective cohort study, females with a history of CABG who underwent CA/I in the period from January 2013 to September 2016 were included. A total of 584 patients were included and divided into two groups: TRA group (49 patients) and TFA group (535 patients). The primary endpoints were $\mathrm{CA}, \mathrm{PT}$, and FT. The means for the primary outcomes were compared between the two using the independent t-score test.

\section{Results}

A total of 584 female patients with a history of CABG had cardiac catheterization from January 2013 to September 2016 at our center. Trans-femoral access accounted for $91.6 \%(n=535)$ of the patients while transradial access accounted for $8.4 \%(n=49)$ of the patients. A comparison of procedural variables between TRA and TFA revealed that there was no statistical significance in procedure time, fluoroscopy time, or the

Received 01/17/2020

Review began 01/21/2020 Review ended 01/22/2020 Published 01/28/2020

\section{(๑) Copyright 2020}

Amro et al. This is an open access article distributed under the terms of the Creative Commons Attribution License CC-BY 3.0., which permits unrestricted use, distribution, and reproduction in any medium, provided the original author and source are credited. contrast volume. The access site crossover rate was $6.12 \%(n=3)$ from radial to femoral while there was a $0 \%$ rate in the femoral to radial access.

\section{Conclusion}

The key findings of this study suggest that in female patients with a prior history of CABG, TRA is an equally reliable and efficacious approach for both diagnostic angiography and intervention compared to TFA.

Categories: Cardiac/Thoracic/Vascular Surgery, Cardiology

Keywords: cabg, right radial artery access, femoral, contrast, fluoroscopy, radiation, female

\section{Introduction}

Cardiovascular disease (CVD) is the leading cause of mortality throughout the Western World for men and women alike [1-2]. Two-thirds of the women who suffer sudden cardiac death have no symptoms prior to their demise [3]. In 2006, the Women's Ischemic Syndrome Evaluation (WISE) study highlighted the importance of heart disease in women [4]. Awareness of CVD has been on the rise but only $54 \%$ of women recognize CVD as the leading cause of death in 2012 [5]. Most of the guidelines, which dictate preventive strategies, diagnostic approaches, and management of CVD, rely on randomized clinical trials (RCT). Unfortunately, women represent only $30 \%$ of the subjects in the RCTs that are utilized as a basis for the American Heart Association (AHA) guidelines [1].

Cardiac catheterization is an important modality in assessing and treating coronary artery disease. In the past, trans-femoral access (TFA) was the benchmark for coronary intervention but, recently, the trans-radial access (TRA) has been shown to be as effective as TFA, if not more [6-7]. The radial vs femoral access for 
coronary intervention (RIVAL) trial reported that TRA had significantly fewer vascular complications, but there were no differences in the outcomes [8]. TRA is also favored because of its attributes of early recovery, ease of hemostasis, and early ambulation [9]. There have been multiple retrospective studies completed, which studied the efficacy of TRA in patients with a prior history of coronary artery bypass grafting (CABG); these studies reported that TRA is an equally feasible and efficient approach in comparison to TFA [9-10].

Most of the studies done in the past have been on the male population. One of the conclusive RADIAL-CABG trials on this topic did not have any female subjects [11]. Limited information is available on the relative merits of TRA as compared to TFA for cardiac catheterization in females who have previously undergone CABG. The purpose of this study was to determine the efficacy and safety of TRA versus TFA in women with prior $C A B G$ surgery who are undergoing coronary angiography/intervention in regard to contrast amount, procedure time, and fluoroscopy time.

\section{Materials And Methods \\ Study design and patient population}

Our study is a retrospective cohort conducted at a single center. The objective of the study was to compare the procedural variable of transradial and transfemoral cardiac catheterization in female patients who had previously undergone CABG surgery. Records from January 2013 to September 2016 were investigated. All female patients undergoing cardiac catheterization (both interventional and diagnostic) with a documented history of CABG were included in the study. There were no exclusion criteria. The study was approved by the institutional review board at Marshall University.

\section{Procedure description}

Transradial catheterization procedures utilized the right radial artery as the access site. After achieving access, intra-arterial nitroglycerin was administered via radial sheath to prevent arterial spasm and intravenous heparin was administered to prevent thrombosis. A post-procedure transradial band was placed at the access site to achieve hemostasis. Transfemoral catheterization procedures utilized either the right or left femoral artery. Post-procedure hemostasis was achieved by employing manual compression or a vascular closure device, at the behest of the operator. Access site preference was at the behest of the operator. This study utilized secondary data, and the exact reason for the specific access site was unavailable.

\section{Endpoints}

The primary endpoint of the study was the radiographic contrast volume administered during the procedure. Secondary endpoints were fluoroscopy time and the time required for the procedure (from time after the administration of the local anesthetic to the time required to complete the procedure with removal of the catheter).

\section{Data collection}

Patient and procedural information was extracted via a retrospective review of the patient's electronic medical records.

\section{Statistical analysis}

Data were tabulated in SPSS version 20 (IBM Corp., Armonk, NY). Categorical variables, such as the sex, procedure type (diagnostic or therapeutic), and access site, were presented as percentages. Continuous variables, such as the volume of radiographic contrast administered during the procedure (primary endpoint), fluoroscopy time, and total procedure time, were presented as mean \pm standard deviation (SD). The test of significance for continuous variables was the independent $t$-test. A P-value of $<0.05$ was considered statistically significant.

\section{Results}

A total of 584 female patients with a history of CABG had cardiac catheterization from January 2013 to September 2016 at our center. Trans-femoral access accounted for $91.6 \%(n=535)$ of the patients while transradial access accounted for $8.4 \%(\mathrm{n}=49)$ of the patients. Baseline characteristics are enumerated in Table 1. The mean age of patients was $64.77+/-11.45$ years. All of the patients were females. From the sample, $7.2 \%$ $(\mathrm{n}=42)$ of patients had ST-elevation myocardial infarction (STEMI), 19.7\% ( $\mathrm{n}=115)$ of patients had nonSTEMI (NSTEMI), 51.9\% $(\mathrm{n}=303)$ of patients had angina, and $20.2 \%(\mathrm{n}=118)$ of patients had unstable angina, and $1 \%(n=6)$ of the patients had no indication stated in the chart for which there was a required cardiac catheterization. Patients that had diagnostic angiographic procedures composed $67.5 \%(n=394)$ of the sample while $32.6 \%(n=190)$ of patients had percutaneous coronary interventions (PCI). 


\section{Cureus}

\begin{tabular}{|c|c|c|c|}
\hline Total $\mathrm{N}=584$ & Radial group $n=49$ & Femoral group $n=535$ & P-values \\
\hline Age (years) & 65.84 & 64.67 & 0.912 \\
\hline Height (cm) & 162.18 & 160.45 & \\
\hline Weight (kg) & 76.4 & 97.86 & \\
\hline BMI $\left(\mathrm{kg} / \mathrm{m}^{2}\right)$ & 29.15 & 37.87 & 0.44 \\
\hline $\mathrm{BSA}\left(\mathrm{m}^{2}\right)$ & 1.8 & 2.38 & 0.82 \\
\hline Number of gratts & 2.71 & 2.75 & 0.62 \\
\hline
\end{tabular}

\section{TABLE 1: Patient's characteristics}

BMI: body mass index; BSA: body surface area

Procedural outcomes are depicted in Table 2. With no statistical significance, compared with TFA, patients undergoing cardiac catheterization via TRA had a lower contrast use (119.39 \pm 58.87 vs $127.43 \pm 68.26$, $\mathrm{P}=0.877$ ), shorter procedure duration ( $39.63 \pm 26.43 \mathrm{~min}$ vs $42.30 \pm 26.87 \mathrm{~min}, \mathrm{P}=0.258$ ), and longer fluoroscopy time (17.13 $\pm 22.63 \mathrm{~min}$ vs. $13.76 \pm 22.63 \mathrm{~min}, \mathrm{P}=0.341)$. The access site crossover rate was $6.12 \%(\mathrm{n}=3)$ from radial to femoral while there was a $0 \%$ rate in the femoral to radial access. All percutaneous coronary intervention (PCI) attempts were successful in both groups, and there were no major peri-procedural complications. There were no minor or major vascular complications in either group.

\begin{tabular}{|c|c|c|c|}
\hline & Transradial access $(n=49)$ & Transfemoral access $(n=535)$ & P-value \\
\hline Contrast volume $(\mathrm{ml})$ & $119.39 \pm 58.87$ & $127.43 \pm 68.26$ & 0.258 \\
\hline Fluoroscopy time (min) & $17.13 \pm 22.63$ & $13.76 \pm 22.63$ & 0.341 \\
\hline Procedural time (min) & $39.63 \pm 26.43$ & $42.30 \pm 26.87$ & 0.887 \\
\hline Crossover & $6.12 \%(n=3)$ & $0 \%(n=0)$ & 0.292 \\
\hline \multicolumn{4}{|l|}{ Procedure type: } \\
\hline${ }^{*} \mathrm{PCl}$ & $28.6 \%(n=14)$ & $32.9 \%(n=176)$ & \\
\hline${ }^{*}$ Diagnostic & $71.4 \%(\mathrm{n}=35)$ & $67.1 \%(n=359)$ & \\
\hline Graft stenting & 8 & 93 & 0.370 \\
\hline Native stenting & 15 & 194 & 0.509 \\
\hline Stents & $1.64 \pm 0.84$ & $1.61 \pm 0.89$ & 0.620 \\
\hline Access site Complications & 0 & 0 & \\
\hline
\end{tabular}

TABLE 2: Comparison of procedural variables between TRA and TFA

TRA: trans-radial access; TFA: trans-femoral access

\section{Discussion}

A well-known complication of cardiac catheterization is contrast-induced nephropathy (CIN). Furthermore, there is an increased risk of CIN with increased contrast amount and, therefore, less contrast amount means less incidence of CIN.

The primary endpoint of our study was to evaluate the contrast volume utilized during the catheterization procedure. The secondary endpoints were the total procedural time and fluoroscopy time. With respect to these procedural variables, our study revealed that there were no statistically significant differences in procedure time, fluoroscopy time, or the contrast volume, which conclude that both access sites are comparable and do not supersede one another. However, per our analysis, TRA does have a higher (6.12\%) 
With the advent of cardiac catheterization in 1929, the femoral approach was the only access site available until 1989, when Campeau reported the first trans-radial diagnostic coronary catheterization [12-13]. Then, for the first time in 1993, Kiemeneij utilized TRA for percutaneous coronary intervention [14]. Subsequently, TRA gained further attention not only because it was a novel access site but also for its multiple positive attributes, such as lower rates of post-procedural complications, earlier hospital discharges, and better patient satisfaction [15-16]. In addition, procedural variables, such as contrast amounts, fluoroscopy time, and procedural duration, also needed consideration in comparison to TFA before TRA could be adapted for mainstream use. This study focused on the comparison of the latter mentioned variables, specifically in women with a prior history of CABG, a patient population that we feel has historically been neglected from such analysis.

Historically, studies on this topic have shown contradictory results both in relation to our study and each other. In 2013, the Radial-CABG Trial reported that a patient undergoing cardiac catheterization via TRA in comparison to TFA required more contrast volume $(142 \pm 39 \mathrm{ml}$ vs. $171 \pm 72 \mathrm{ml}, \mathrm{p}<0.01)$, increased radiation exposure, and longer procedural time $(21.9 \pm 6.8 \mathrm{~min}$ vs. $34.2 \pm 14.7 \mathrm{~min}, \mathrm{p}<0.01)$; this trial also reported a $17.2 \%$ crossover rate in the TRA arm of their study. Conversely, in 2016, Kedev et al. reported that TRA procedures required less contrast 100 (45-300) $\mathrm{ml}$ compared to TFA procedures $136(46-350) \mathrm{ml}$ (p-value 0.001) [7]. Rao et al. reported similar results, finding higher contrast volume use among TFA patients [17]. It is important to note, however, that the registry studies done by Kedev et al. and Rao et al. did not distinguish between $C A B G$ and non-CABG patients. For this reason, our study is best aligned for comparison with the RADIAL-CABG trial, although our particular focus is on the female population while RADIAL-CABG included only male patients.

Our study results contradict RADIAL-CABG in terms of the procedural variables, but we are in partial concordance due to the finding of a $6.12 \%(n=3)$ crossover rate in TRA to TFA [11]. In 2015, He et al. reported findings similar to our results and included an approximately $20 \%$ female population. He et al. highlighted that there was no difference between the procedure time and success rate and that the TRA was safe and feasible for patients with a prior history of CABG [9]. In 2016, a meta-analysis by Rigattieri et al. reported no statistical difference in procedural time (mean difference 3.24 minutes, $95 \% \mathrm{CI}-1.76$ to $8.25, \mathrm{p}=0.20$ ), contrast volume (mean difference $-2.58 \mathrm{ml}, 95 \% \mathrm{CI}-18.36$ to $13.20, \mathrm{p}=0.75$ ), and fluoroscopy time (mean difference 0.62 minutes, $95 \% \mathrm{CI}-0.83$ to $2.07, \mathrm{p}=0.40$ ) when TFA is compared to TRA in patients with CABG; however, there was a higher crossover rate (OR 7.0, 95\% CI 2.74 to $17.87, \mathrm{p}<0.0001)$ in TRA procedures. Our analysis is in complete agreement with the aforementioned finding of Rigattieri et al [18].

Although TRA is gaining favor over the TFA, there are several caveats to consider. The most prevalent challenge when doing cardiac catheterization via the radial artery is obtaining access but once the access is achieved, the rate of successful cardiac catheterization is similar to TFA [15,19]. A study by Guédès et al. demonstrated that the majority of TRA procedure failures were due to the inability of the operator to puncture the artery; as per their recommendation, this hurdle can be surpassed if both radial arteries are attempted first prior to TFA conversion [20]. The caliber of the radial artery is small, as reported by Yoo et al. In men, the caliber is $2.69 \pm 0.40 \mathrm{~mm}$ while it is $2.43 \pm .038 \mathrm{~mm}$ in women. The small caliber of the radial artery makes it susceptible to spasm, which makes the manipulation of the catheter difficult and increases the risk of procedural failure or conversion [15,21-22]. Another factor that influences the TRA procedure success is lower catheter support, which decreases maneuverability and leads to procedure failure. Radial artery anatomical variation can play an integral role in the procedure outcome [15]. Valsecchi et al. studied the anatomical variation of the radial artery and its effect on the outcome of the procedure. The reported reasoning for failure and procedure crossover was due to a tortuous radial artery without stenosis, renal artery stenosis, hypoplastic radial artery, presence of radioulnar loop, the abnormal origin of the radial artery, and the retroesophageal origin of the subclavian artery [23].

Even though such challenges exist, TRA is still recommended, as per the guidelines of the AHA "Radial-First Strategy," which should be considered when attempting cardiac catheterization [24]. There are multiple factors associated with TRA catheterization failure, namely, female sex, age (>75), history of CABG, cardiogenic shock, and short stature [24-27]. In light of this, the sample for our study was very high-risk, as we had included patients with all but one risk factor, specifically cardiogenic shock; even then, our results indicate that only $6.12 \%(n=3)$ of the patients had to be converted to TFA from TRA while the remaining procedures were successful. Rathore et al. reported that a lower body mass index (BMI) was an independent factor for the failure of TRA but our analysis revealed that apart from the conversion, the remaining TRA procedures were successful although the BMI in our patients ranged from 20.14 to 50.99 with a mean of $29.15 \pm 5.7[28]$.

According to our data, $8.39 \%(n=49)$ patients had procedures via TRA while $91.6 \%(n=535)$ patients had procedure via TFA. This disproportion in our data is due to the performing physician's procedure preference. Upon further observation into the thought processes of various physicians, we were able to deduce that the access site of choice by most of the operators for CABG patients is trans-femoral but, even then, $8.39 \%$ of the patients had procedures via TRA. The success rate for the said TRA procedures was $100 \%$ with the exception of the cross-over patients. Furthermore, our study showed that all PCI attempts were successful in both 
groups, and there were no major peri-procedural complications. Also, there were no minor or major vascular complications in either group. However, given the fact that our study is a retrospective study, we suspect that there might be minor vascular complications that might have not been reported especially the majority of our patients were outpatients with same-day discharge.

The debate about using TRA in female patients is vital. It would be noteworthy to mention that the anatomical difference that makes TRA challenging in females also makes the TFA procedures prone to a higher risk of bleeding. In 2019, Kwok et al. reported higher crude bleeding rates in TFA (2.86\%) and TRA (1.1\%). This was attributed to the anatomy of the common femoral artery (CFA); the CFA is shorter and smaller in diameter, which inadvertently decreases the area for safe vascular puncture [29]. The Study of Access Site for Enhancement of PCI (SAFE-PCI) for women trial reported in 2018 that TRA and guided TFA presented no statistical differences in bleeding events and vascular complications [30]. In 2015, Pandie et al. reported the results of the RIVAL trial for women with ACS. According to their analysis, major vascular complications were significantly lower in women with TRA access: $3.1 \%$ vs $6.1 \%$ (hazard ratio (HR) 0.5 ; $95 \%$ CI 0.32 to $0.78 \mathrm{p}=0.002$ ) [6].

Gender bias in the current literature is a troublesome limitation [1]. Guidelines based on the current literature would be inadequate and subpar in guiding physicians to provide the most effective patient care. The most important resource for our topic is the meta-analysis by Rigattieri et al., which only has female representation in $21.17 \%$ of the sample [18]. Such discrepancies in sample collection hinder the generalizability of the findings. Although multiple patient studies have shown TRA to be as effective as TFA in regards to procedural outcomes and safer in regards to access site complications, TRA is not frequently employed for female patients with a prior history of CABG; this is evident in our study, as only $8.39 \%$ of the patients had procedures done via TRA.

\section{Limitations}

One of the major limitations of this study was the study design. This was a one-center, retrospective study with a lack of documentation provided about operator site preference. The disproportionate representation of the access site is also attributable to the retrospective nature of the study; this limited the statistical analysis of PCI in native and graft arteries, as the power of the sample was too low to achieve statistical significance. Authors have initially decided on not doing an analysis based on graft number, graft type, or any combinations of these because such groupings would lead to small sample sizes and would not be able to exclude other confounding factors. Finally, the secondary data were obtained from the catheterization laboratory; hence, the post-procedure complications were not evaluated.

\section{Conclusions}

The key findings of this study suggest that in female patients with a prior history of CABG, TRA is an equally reliable and efficacious approach for both diagnostic angiography and intervention as compared to TFA. However, due to the limitations of this retrospective study, we recommend a multicenter randomized control trial to be done on this population of patients to compare TRA and TFA and include an analysis of the various CABG subgroups.

\section{Additional Information \\ Disclosures}

Human subjects: Consent was obtained by all participants in this study. Marshall University Institutional Review Board \#1 (Medical), Huntington, WV issued approval 974841-4. Animal subjects: All authors have confirmed that this study did not involve animal subjects or tissue. Conflicts of interest: In compliance with the ICMJE uniform disclosure form, all authors declare the following: Payment/services info: All authors have declared that no financial support was received from any organization for the submitted work. Financial relationships: All authors have declared that they have no financial relationships at present or within the previous three years with any organizations that might have an interest in the submitted work. Other relationships: All authors have declared that there are no other relationships or activities that could appear to have influenced the submitted work.

\section{References}

1. Shen L, Melloni C: Representation of women in randomized clinical trials of cardiovascular disease prevention. Curr Cardiovasc Risk Rep. 2014, 8:1-5. 10.1007/s12170-014-0390-9

2. Hochman JS, Tamis JE, Thompson TD, et al.: Sex, clinical presentation, and outcome in patients with acute coronary syndromes. N Engl J Med. 1999, 341:226-232. 10.1056/NEJM199907223410402

3. Roger VL, Go AS, Lloyd-Jones DM, et al.: Heart disease and stroke statistics-2012 update. A report from the American Heart Association. Circulation. 2012, 125:e2-e220. 10.1161/CIR.0b013e31823ac046

4. Shaw LJ, Bairey Merz CN, Pepine CJ, et al.: Insights from the NHLBI-Sponsored Women's Ischemia Syndrome Evaluation (WISE) study. J Am Coll Cardiol. 2006, 47:S4-S20. 10.1016/j.jacc.2005.01.072

5. Mosca L, Mochari-Greenberger H, Dolor RJ, Newby LK, Robb KJ: Twelve-year follow-up of American women's awareness of cardiovascular disease risk and barriers to heart health. Circ Cardiovasc Qual Outcomes. 2010, 3:120-127. 10.1161/CIRCOUTCOMES.109.915538 
6. Pandie S, Mehta SR, Cantor WJ, et al.: Radial versus femoral access for coronary angiography/intervention in women with acute coronary syndromes: insights from the RIVAL trial (radial vs femoral access for coronary intervention). JACC Cardiovasc Interv. 2015, 8:505-512. 10.1016/j.jcin.2014.11.017

7. Kedev S, Sukmawan R, Kalpak O, et al.: Transradial versus transfemoral access for female patients who underwent primary PCI in STEMI: two years follow-up data from acute STEMI interventional registry. Int J Cardiol. 2016, 217:16-20. 10.1016/j.ijcard.2016.06.222

8. Jolly SS, Yusuf S, Cairns J, et al.: Radial versus femoral access for coronary angiography and intervention in patients with acute coronary syndromes (RIVAL): a randomised, parallel group, multicentre trial. Lancet. 2011, 377:1409-1420. 10.1016/S0140-6736(11)60404-2

9. He P-Y, Yang Y-J, Qiao S-B, et al.: A comparison of the transradial and transfemoral approaches for the angiography and intervention in patients with a history of coronary artery bypass surgery: in-hospital and 1-year follow-up results. Chin Med J. 2015, 128:762-767. 10.4103/0366-6999.152488

10. Bundhoo SS, Earp E, Ivanauskiene T, et al.: Saphenous vein graft percutaneous coronary intervention via radial artery access: Safe and effective with reduced hospital length of stay. Am Heart J. 2012, 164:468-472. 10.1016/j.ahj.2012.07.029

11. Michael TT, Alomar M, Papayannis A, et al.: A randomized comparison of the transradial and transfemoral approaches for coronary artery bypass graft angiography and intervention: The RADIAL-CABG Trial (RADIAL versus femoral access for coronary artery bypass graft angiography and intervention). JACC Cardiovasc Interv. 2013, 6:1138-1144. 10.1016/j.jcin.2013.08.004

12. Bourassa MG: The history of cardiac catheterization. Can J Cardiol. 2005, 21:1011-1014.

13. Campeau L: Percutaneous radial artery approach for coronary angiography. Cathet Cardiovasc Diagn. 1989, 16:3-7. 10.1002/ccd.1810160103

14. Kiemeneij F, Laarman GJ: Percutaneous transradial artery approach for coronary stent implantation. Cathet Cardiovasc Diagn. 1993, 30:173-178. 10.1002/ccd.1810300220

15. Agostoni P, Biondi-Zoccai GGL, De Benedictis ML, et al.: Radial versus femoral approach for percutaneous coronary diagnostic and interventional procedures. J Am Coll Cardiol. 2004, 44:349-356. 10.1016/j.jacc.2004.04.034

16. Jolly SS, Amlani S, Hamon M, Yusuf S, Mehta SR: Radial versus femoral access for coronary angiography or intervention and the impact on major bleeding and ischemic events: a systematic review and meta-analysis of randomized trials. Am Heart J. 2009, 157:132-140. 10.1016/j.ahj.2008.08.023

17. Rao SV, Hess CN, Barham B, et al.: A registry-based randomized trial comparing radial and femoral approaches in women undergoing percutaneous coronary intervention. JACC Cardiovasc Interv. 2014, 7:857-867. 10.1016/j.jcin.2014.04.007

18. Rigattieri S, Sciahbasi A, Brilakis ES, et al.: Meta-analysis of radial versus femoral artery approach for coronary procedures in patients with previous coronary artery bypass grafting. Am J Cardiol. 2016, 117:1248-1255. 10.1016/j.amjcard.2016.01.016

19. Schussler JM: Effectiveness and safety of transradial artery access for cardiac catheterization . Proc (Bayl Univ Med Cent). 2011, 24:205-209. 10.1080/08998280.2011.11928716

20. Guédès A, Dangoisse V, Gabriel L, Jamart J, Chenu P, Baudouin Marchandise B, Schroeder E: Low rate of conversion to transfemoral approach when attempting both radial arteries for coronary angiography and percutaneous coronary intervention: a study of 1,826 consecutive procedures. J Invasive Cardiol. 2010, 22:391-397.

21. Dehghani P, Mohammad A, Bajaj R, et al.: Mechanism and predictors of failed transradial approach for percutaneous coronary interventions. JACC Cardiovasc Interv. 2009, 2:1057-1064. 10.1016/J.JCIN.2009.07.014

22. Yoo B-S, Yoon J, Ko J-Y, Kima J-Y, Lee S-H, Hwang S-O, Choe K-H: Anatomical consideration of the radial artery for transradial coronary procedures: arterial diameter, branching anomaly and vessel tortuosity. Int J Cardiol. 2005, 101:421-427. 10.1016/j.ijcard.2004.03.061

23. Valsecchi O, Vassileva A, Musumeci G, et al.: Failure of transradial approach during coronary interventions: anatomic considerations. Catheter Cardiovasc Interv. 2006, 67:870-878. 10.1002/ccd.20732

24. Mason PJ, Shah B, Tamis-Holland JE, et al.: An update on radial artery access and best practices for transradial coronary angiography and intervention in acute coronary syndrome: a scientific statement from the American Heart Association. Circ Cardiovasc Interv. 2018, 11 :e000035. 10.1161/HCV.0000000000000035

25. Hu J, Cai X, Wang X, Chen L, Xu D, Li J: Risk factors of failed transradial approach for percutaneous coronary interventions in Chaoshan Chinese: a locally retrospective analysis. Int J Clin Exp Med. 2015, 8:11770-11776.

26. Carvalho MS, Calé R, Gonçalves P de A, et al.: Predictors of conversion from radial into femoral access in cardiac catheterization. Arq Bras Cardiol. 2015, 104:401-408. 10.5935/abc.20150017

27. Abdelaal E, Brousseau-Provencher C, Montminy S, et al.: Mini-focus on radial access. Risk score, causes, and clinical impact of failure of transradial approach for percutaneous coronary interventions. JACC Cardiovasc Interv. 2013, 6:1129-1137. 10.1016/j.jcin.2013.05.019

28. Rathore S, Stables RH, Pauriah M, et al.: Impact of length and hydrophilic coating of the introducer sheath on radial artery spasm during transradial coronary intervention: a randomized study. JACC Cardiovasc Interv. 2010, 3:475-483. 10.1016/J.JCIN.2010.03.009

29. Kwok CS, Kontopantelis E, Kunadian V, et al.: Effect of access site, gender, and indication on clinical outcomes after percutaneous coronary intervention: Insights from the British Cardiovascular Intervention Society (BCIS). Am Heart J. 2015, 170:164-172. 10.1016/j.ahj.2015.04.018

30. Koshy LM, Aberle LH, Krucoff MW, et al.: Comparison of radial access, guided femoral access, and nonguided femoral access among women undergoing percutaneous coronary intervention. J Invasive Cardiol. 2017, 30:18-22. 